\title{
Overexpression of regucalcin suppresses gene expression of insulin signaling-related proteins in cloned rat hepatoma H4-II-E cells: Involvement of insulin resistance
}

\author{
CHIKAGE NAKASHIMA and MASAYOSHI YAMAGUCHI \\ Laboratory of Endocrinology and Molecular Metabolism, Graduate School of Nutritional Sciences, \\ University of Shizuoka, 52-1 Yada, Suruga-ku, Shizuoka 422-8526, Japan
}

Received June 3, 2007; Accepted July 24, 2007

\begin{abstract}
Overexpression of regucalcin has been shown to enhance glucose utilization and lipid production in the cloned rat hepatoma H4-II-E cells in vitro, and it induces insulin resistance. The effect of regucalcin on the gene expression of insulin signaling-related proteins was investigated in the cloned rat hepatoma H4-II-E cells overexpressing regucalcin in vitro. The hepatoma cells (wild-type) and stable regucalcin/ pCXN2-transfected cells (transfectants) were cultured for $72 \mathrm{~h}$ in a medium containing $10 \%$ fetal bovine serum (FBS) to obtain subconfluent monolayers. Cells with subconfluency were cultured for 24,48 , or $72 \mathrm{~h}$ in a medium containing either vehicle or insulin $\left(10^{-9}-10^{-7} \mathrm{M}\right)$ with or without supplementation of glucose $(10,25$, or $50 \mathrm{mg} / \mathrm{ml}$ of medium). The expression of rat insulin receptor (Insr), phosphatidylinositol 3-kinase (PI3K), glucose transporter 2 (GLUT 2), or glyceroaldehyde-3-phosphate dehydrogenase (G3PDH) mRNAs was examined using reverse transcription-polymerase chain reaction analysis with specific primers. GLUT 2 mRNA expression was significantly increased in the transfectants, while Insr, PI3K, and G3PDH mRNA levels were not significantly changed in the transfectants. Culture with insulin $\left(10^{-8}\right.$ or $\left.10^{-7} \mathrm{M}\right)$ caused a significant increase in PI3K mRNA levels in wild-type cells cultured for 24 or $48 \mathrm{~h}$, while it had no effect on Insr mRNA levels. The supplementation of glucose $(10,25$, or $50 \mathrm{mg} / \mathrm{ml})$ caused a significant increase in Insr and PI3K mRNA levels in wild-type cells. The effect of insulin or glucose supplementation on these gene expression levels was not seen in the transfectants. The combination of insulin $\left(10^{-7} \mathrm{M}\right)$ and glucose $(50 \mathrm{mg} / \mathrm{ml})$ caused a significant increase in Ins and PI3K mRNA levels in wild-type cells. Such an effect was not seen in the transfectants. Culture with
\end{abstract}

Correspondence to: Dr Masayoshi Yamaguchi, Laboratory of Endocrinology and Molecular Metabolism, Graduate School of Nutritional Sciences, University of Shizuoka, 52-1 Yada, Suruga-ku, Shizuoka 422-8526, Japan

E-mail: yamaguch@u-shizuoka-ken.ac.jp

Key words: regucalcin, insulin, insulin receptor, phosphatidylinositol 3-kinase, glucose transporter 2, liver cells insulin or glucose supplementation failed to have a significant effect on GLUT2 and G3PDH mRNA levels in the wild-type cells or transfectants. This study demonstrates that overexpression of regucalcin suppresses the enhancing effect of insulin or glucose on the gene expression of insulin signalingrelated proteins in the cloned rat hepatoma H4-II-E cells.

\section{Introduction}

The gene of regucalcin, which was found as a novel $\mathrm{Ca}^{2+}$ binding protein not including the EF-hand motif (1-4), is highly conserved in vertebrate species $(4,5)$. Regucalcin genes are localized on chromosome $\mathrm{X}(6,7)$. The expression of regucalcin mRNA is mediated through a $\mathrm{Ca}^{2+}$-signaling mechanism which is involved in transcriptional factors (including AP-1, NF1-A1, and RGPR-p117) for the enhancement of regucalcin gene promoter activity (8-11).

Regucalcin has been demonstrated to play a multifunctional role as a regulatory protein in the intracellular signaling process in many cell types (reviewed in refs. 12-14). Regucalcin plays a role in the maintenance of intracellular $\mathrm{Ca}^{2+}$ homeostasis, the inhibitory regulation of various $\mathrm{Ca}^{2+}$ dependent protein kinases, tyrosine kinases, cytosolic protein synthesis, nuclear DNA and RNA syntheses in many cell types (12-14). In addition, regucalcin has an activatory effect on $\mathrm{Ca}^{2+}$-ATPase (calcium pump enzymes), proteolysis (protease), and superoxide dismutase in cells (14-16). Regucalcin has been shown to have suppressive effects on cell proliferation $(17,18)$ and apoptotic cell death $(19,20)$. Thus, regucalcin plays a pivotal role in maintaining cell homeostasis and function (14).

Regucalcin transgenic rats have been generated to determine the physiologic role of endogenous regucalcin in vivo (21). These animals have been found to manifest bone loss (22) and hyperlipidemia (23), suggesting the pathophysiologic role of regucalcin, although the mechanisms have not been fully determined.

Overexpression of regucalcin has been shown to enhance glucose utilization and lipid production in the cloned rat hepatoma H4-II-E cells in vitro, and to induce insulin resistance in the cells (24). This study was undertaken to determine whether overexpression of regucalcin has an inhibitory effect on gene expression of insulin signalingrelated proteins in the cloned rat hepatoma H4-II-E cells 
in vitro. We found that overexpression of regucalcin had a suppressive effect on the enhancement of Insr and PI3K mRNA expression in the H4-II-E cells cultured with insulin or glucose supplementation.

\section{Materials and methods}

Chemicals. $\alpha$-Minimal essential medium ( $\alpha$-MEM) and penicillin-streptomycin $(5,000 \mathrm{U} / \mathrm{ml}$ penicillin: $5,000 \mu \mathrm{g} / \mathrm{ml}$ streptomycin) were obtained from Gibco Laboratories (Grand Island, NY). Fetal bovine serum (FBS) and insulin were obtained from Sigma Chemical Co., (St. Louis, MO). Glucose and additional chemicals were purchased from Wako Pure Chemicals (Osaka, Japan). The reagents used were dissolved in distilled water, and certain reagents were passed through ion exchange resin to remove metal ions.

Regucalcin transfectants. Regucalcin transfectants, which overexpressed regucalcin in the cloned rat hepatoma H4-II-E cells, were used in these experiments as previously reported (25). The cDNA encoding rat regucalcin was isolated and cloned into the pBluescript vector (4). The regucalcin cDNA contains PstI site downstream of the translational stop codon, and a PstI site and an EcoRI upstream of the regucalcin cDNA. The EcoRI fragment (containing the complete coding cDNA) was cloned into the EcoRI site of the pCXN2 expression vector. The resultant plasmid was designated as regucalcin/pCXN2 (25).

For transient transfection assay, the H4-II-E cells were grown on 35-mm dishes to $70 \%$ confluence. Each regucalcin/ pCXN2 and pCXN2 vector alone was transfected into the H4-II-E cells using the synthetic cationic lipid component, Tfx-20 reagent, according to the manufacturer's instructions (Promega, Madison WI). After $24 \mathrm{~h}$, neomycin $(1.0 \mathrm{mg} / \mathrm{ml}$ Geneticin G418, Sigma) was added to the cultures for selection, and cells were plated at a limiting dilution. Multiple surviving clones were isolated, transferred to $35-\mathrm{mm}$ dishes, and grown in the medium without neomycin. We confirmed that regucalcin was stably expressed in the transfectants using Western blot analysis for regucalcin protein levels (25). For the experiments, the transfectants were cultured for $72 \mathrm{~h}$ in $\alpha$-MEM containing $10 \%$ FBS.

Cell culture. The cloned rat hepatoma H4-II-E cells and transfectants of H4-II-E cells $\left(1.0 \times 10^{5}\right)$ were maintained for $72 \mathrm{~h}$ in $\alpha$-MEM supplemented with $50 \mathrm{U} / \mathrm{ml}$ penicillin and $50 \mu \mathrm{g} / \mathrm{ml}$ streptomycin in humidified $5 \% \mathrm{CO}_{2} / 95 \%$ air at $37^{\circ} \mathrm{C}$ to obtain subconfluent monolayers (25). For the experiments, cells were cultured for 24-72 h in medium containing either vehicle or insulin with or without glucose supplementation in the absence of FBS. After culture, the medium was pooled, and then cells were washed three times with phosphate-buffered saline (PBS).

Determination of specific mRNA by RT-PCR. Total RNAs were prepared as described previously (26). After culture, cells were washed three times with ice-cold PBS, and then cells were homogenized in buffer solution containing $4 \mathrm{M}$ guanidinium thiocyanate, $24 \mathrm{mM}$ sodium citrate $(\mathrm{pH} 7.0)$, $0.5 \%$ sarcosyl, and isoamyl alcohol, and the phases were separated by centrifugation at $10,000 \mathrm{x}$ g for $20 \mathrm{~min}$ at $4^{\circ} \mathrm{C}$. RNA located in the aqueous phase was precipitated with isopropanol at $-20^{\circ} \mathrm{C}$. RNA precipitates were pelleted by centrifugation, and the pellets were redissolved in diethyl pyrocarbonate-treated water.

RT-PCR was preformed with a Titan ${ }^{\mathrm{TM}}$ One Tube RTPCR kit (Roche Molecular Biochemicals) as recommended by the supplier. Primers for amplification of rat insulin receptor (Insr) cDNA were: 5'-TCCCCTGGATCCCATATCAG-3' (sense strand, positions 2226-2245 of cDNA sequence) and 5'-GGAGCTTCAGCCCTTTGAGA-3' (antisense strand, positions 2395-2414) (27). The pair of oligonucleotide primers was designed to amplify a 189-bp sequence from the mRNA of rat Insr.

Primers for amplification of rat phosphatidylinositol 3kinase (PI3K) cDNA were: 5'-GATGTGGCTGACGCAGA AAG-3' (sense strand, positions 669-688 of cDNA sequence) and 5'-CTCGTTTCCCTCGCAATAGG-3' (antisense strand, positions 853-872) (28). The pair of oligonucleotide primers was designed to amplify a 204-bp sequence from the mRNA of rat PI3K.

Primers for amplification of rat glucose transporter 2 (GLUT 2) cDNA were: 5'-TTCATGTCGCTGGGACTGGT-3' (sense strand, position 1246-1265 of cDNA sequence) and 5'-CCACCCCAGCAAAAAGGAAG-3' (antisense strand, positions 1500-1519) (29). The pair of oligonucleotide primers was designed to amplify a 274-bp sequence from the mRNA of rat GLUT 2.

For semi-quantitative PCR, G3PDH was used as an internal control to evaluate total RNA input. Primers for amplification of G3PDH cDNA were, 5'-GATTTGGCCGTATCGGA CGC-3' (sense strand) and 5'-CTCCTTGGAGGCCATGT AGG-3' (antisense strand). The pair of oligonucleotide primers was designed to amplify a 977-bp sequence from the mRNA of rat G3PDH.

RT-PCR was performed using a reaction mixture $(20 \mu \mathrm{l})$ containing $2 \mu \mathrm{g}$ of total RNAs, the supplied RT-PCR buffer, Titan $^{\mathrm{TM}}$ enzyme mix (AMV and Expand ${ }^{\mathrm{TM}}$ High Fidelity), $0.2 \mathrm{mM}$ dNTP, $5 \mathrm{mM}$ dithiothreitol, $5 \mathrm{U}$ RNase inhibitor, and $0.3 \mu \mathrm{M}$ primers. Samples were incubated at $50^{\circ} \mathrm{C}$ for $30 \mathrm{~min}$, and then amplified for 30 cycles under the following conditions: denaturation for $30 \mathrm{sec}$ at $94^{\circ} \mathrm{C}$, annealing for $30 \mathrm{sec}$ at $56^{\circ} \mathrm{C}$, and extension for $60 \mathrm{sec}$ at $62^{\circ} \mathrm{C}$. The amplified products were separated by electrophoresis on a $1.5 \%$ agarose gel and visualized by ethidium bromide staining. Image density was quantified with a FluoroImager SI (Amersham Biosciences, Piscataway, NJ).

Statistical analysis. Data are expressed as the mean \pm standard error of the mean (SEM). Statistical differences were analyzed using the Student's t-test. P-values $<0.05$ were considered to indicate statistically significant differences. Also, we used an ANOVA multiple comparison test to compare the treatment groups.

\section{Results}

Change in gene expression of insulin signaling-related proteins in H4-II-E cells overexpressing regucalcin. The cloned rat hepatoma H4-II-E cells (wild-type) and stable 
A. Insr

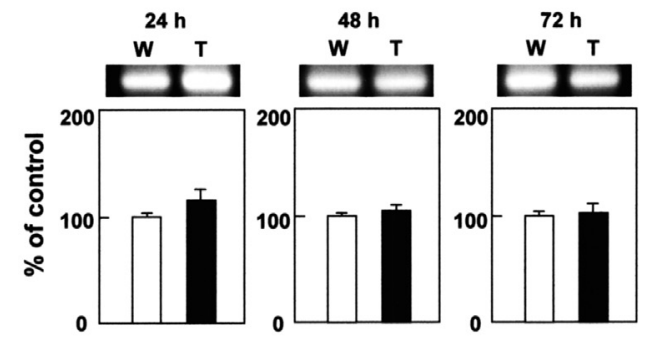

\section{GLUT 2}

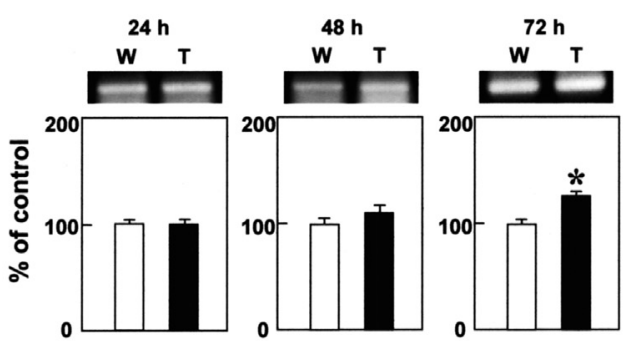

B. PI3K

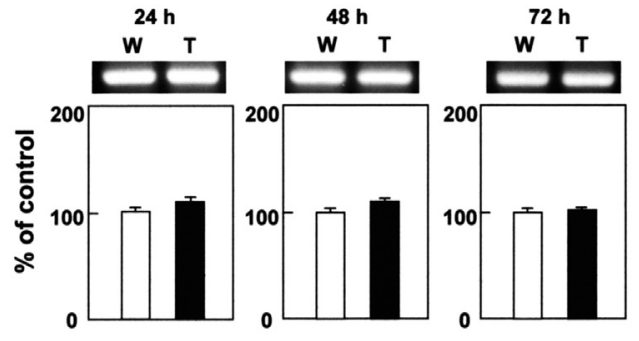

D. G3PDH

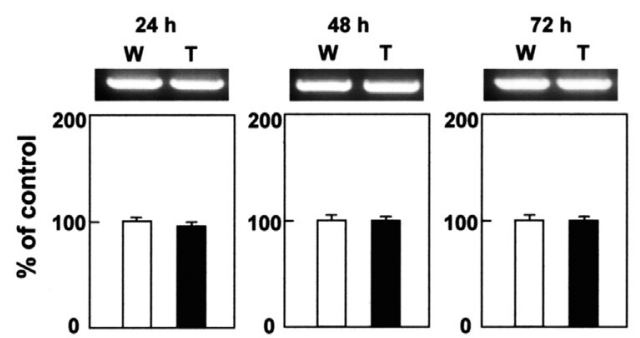

Figure 1. Change in insulin receptor (Insr) (A), phosphatidylinositol 3-kinase (PI3K) (B), glucose transporter 2 (GLUT 2) (C), or G3PDH (D) mRNA expression in cloned rat hepatoma H4-II-E cells overexpressing regucalcin. Wild-type (W) or regucalcin/pCXN2-transfected cells (T) were cultured for $72 \mathrm{~h}$ in a medium containing FBS $(10 \%)$ to obtain subconfluent monolayers. After medium change, cells with subconfluency were cultured for 24 , 48 , and $72 \mathrm{~h}$ in medium without FBS. The figure shows one of four experiments with separate samples. The densitometric data for mRNA levels were indicated as $\%$ of the control (none) of wild-type cells (mean \pm SEM of four experiments). ${ }^{*} \mathrm{p}<0.01$ compared with the value of wild-type cells
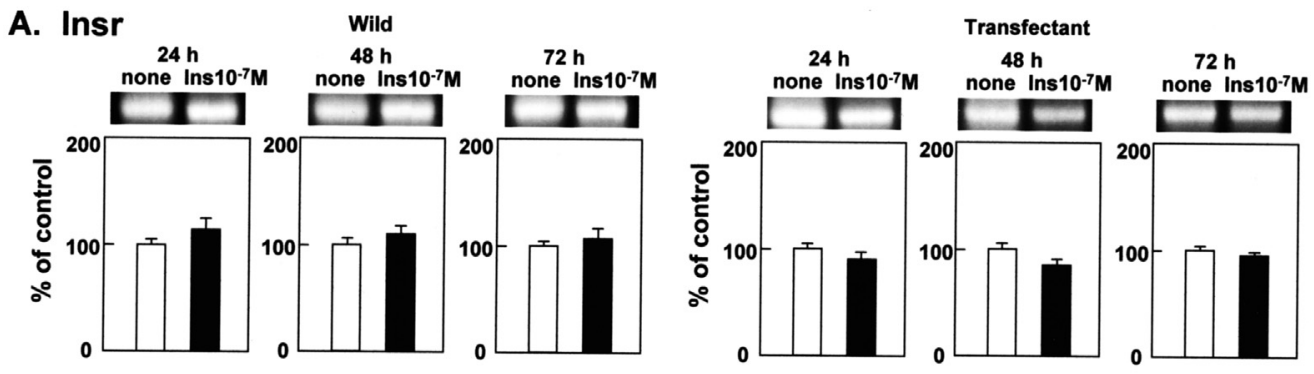

B. PI3K
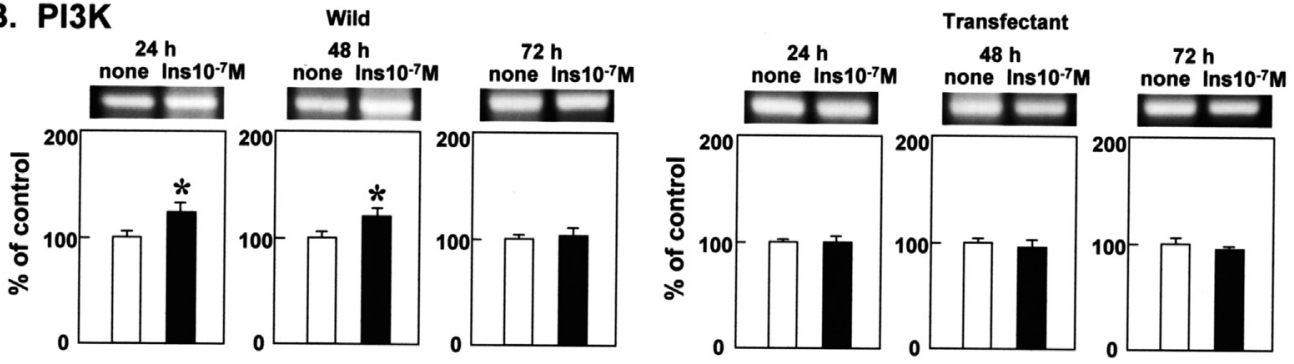

Figure 2. Effect of insulin on insulin receptor (Insr) (A) or phosphatidylinositol 3-kinase (PI3K) (B) mRNA expression in the cloned rat hepatoma H4-II-E cells (wild-type; W) or regucalcin/pCXN2-transfected cells (T). Cells were cultured for $72 \mathrm{~h}$ in medium containing FBS (10\%) to obtain subconfluent monolayers. After medium change, cells with subconfluency were cultured for 24,48 , and $72 \mathrm{~h}$ in medium containing either vehicle or insulin $\left(10^{-7} \mathrm{M}\right)$. The figure shows one of four experiments with separate samples. The densitometric data for mRNA levels were indicated as \% of the control (none) of wild-type cells (mean $\pm \mathrm{SEM}$ of four experiments). ${ }^{\mathrm{p}} \mathrm{p}<0.01$, compared with the control (none) value.

regucalcin/pCXN2-transfected cells (transfectants) were cultured for $72 \mathrm{~h}$ in a medium containing $10 \%$ FBS to obtain subconfluent monolayers. Cells with subconfluency were further cultured for 24,48 or $72 \mathrm{~h}$ in a medium without FBS. GLUT 2 mRNA expression was significantly increased in the transfectants cultured for $72 \mathrm{~h}$ (Fig. 1C). The expression of insulin receptor (Insr), phosphatidylinositol 3-kinase (PI3K), and G3PDH mRNAs was not significantly changed in the transfectants (Fig. 1A, B, and D).

Effect of insulin on gene expression of insulin signalingrelated proteins in H4-II-E cells overexpressing regucalcin. The wild-type cells and the transfectants with subconfluency were cultured for 24,48 , or $72 \mathrm{~h}$ in a medium containing either 
A. GLUT 2
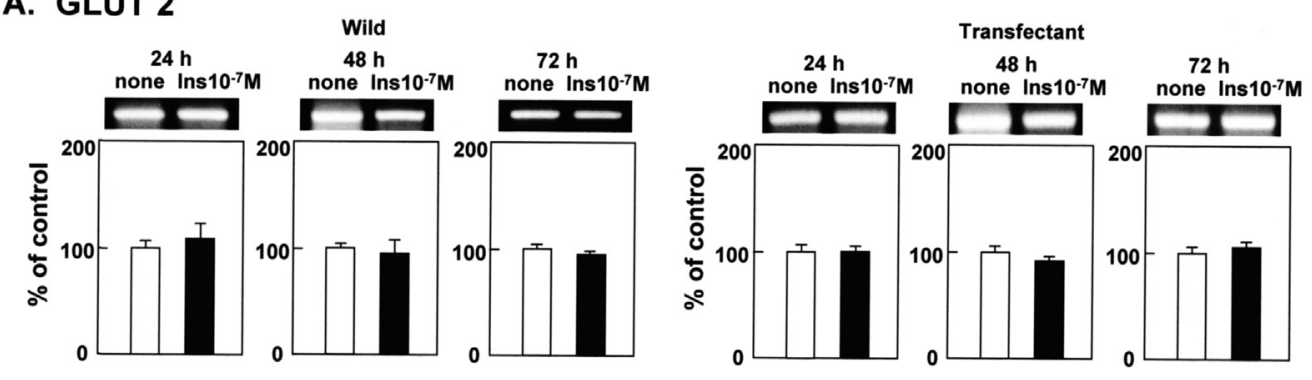

B. G3PDH
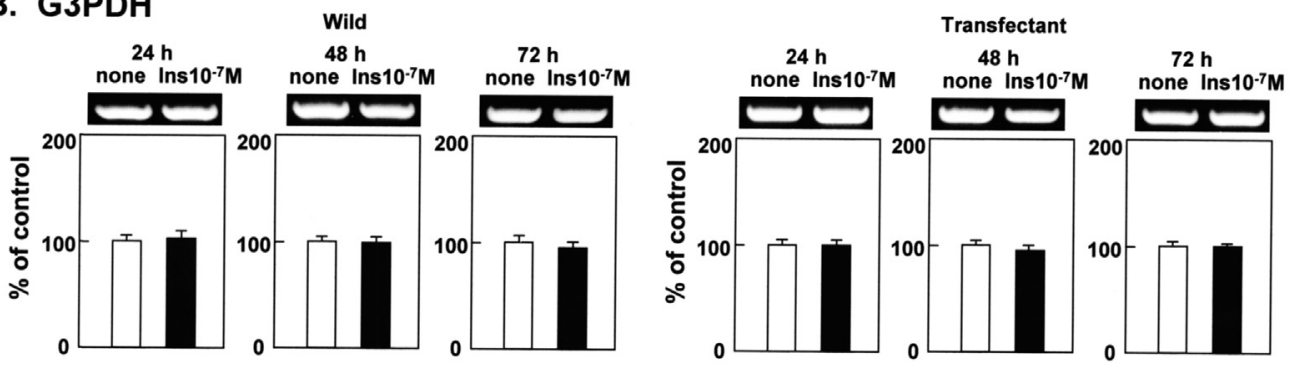

Figure 3. Effect of insulin on glucose transporter 2 (GLUT 2) (A) or G3PDH (B) mRNA expression in the cloned rat hepatoma H4-II-E cells (wild-type; W) or regucalcin/pCXN2-transfected cells (T). Cells were cultured for $72 \mathrm{~h}$ in medium containing FBS (10\%) to obtain subconfluent monolayers. After medium change, cells with subconfluency were cultured for 24,48 , and $72 \mathrm{~h}$ in medium containing either vehicle or insulin $\left(10^{-7} \mathrm{M}\right)$. The figure shows one of four experiments with separate samples. The densitometric data for mRNA levels were indicated as $\%$ of the control (none) of wild-type cells (mean \pm SEM of four experiments). Data were not significant.

A. Insr

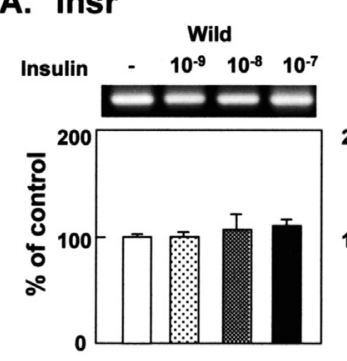

C. GLUT 2

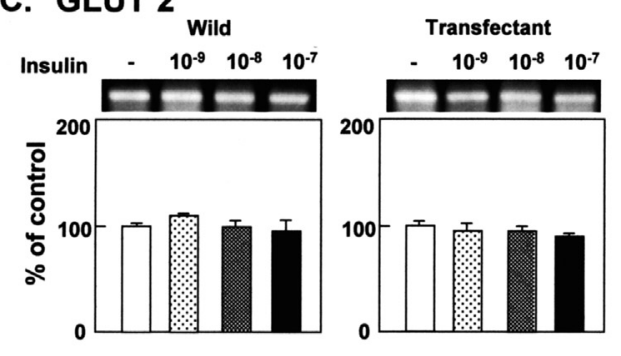

B. PI3K

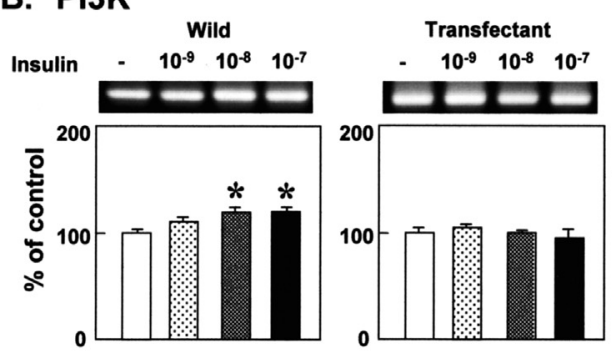

D. G3PDH

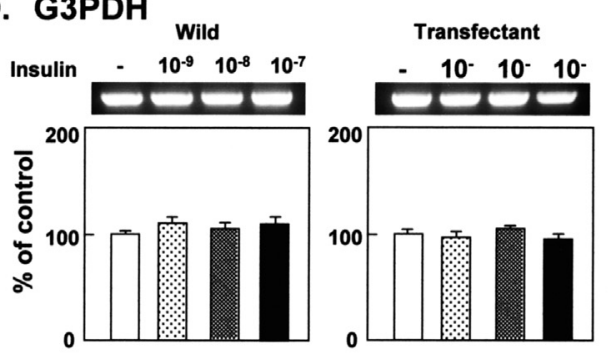

Figure 4. Effect of insulin on insulin receptor (Insr) (A), phosphatidylinositol 3-kinase (PI3K) (B), glucose transporter 2 (GLUT 2) (C), or G3PDH (D) mRNA expression in the cloned rat hepatoma H4-II-E cells (wild-type; W) or regucalcin/pCXN2-transfected cells (T). Cells were cultured for $72 \mathrm{~h}$ in a medium containing FBS (10\%) to obtain subconfluent monolayers. After medium change, cells with subconfluency were cultured for $24 \mathrm{~h}$ in medium containing either vehicle or insulin $\left(10^{-9}-10^{-7} \mathrm{M}\right)$. The figure shows one of four experiments with separate samples. The densitometric data for mRNA levels were indicated as $\%$ of the control (none) of wild-type cells (mean \pm SEM of four experiments). ${ }^{*} \mathrm{p}<0.01$, compared with the control (none) value.

vehicle or insulin $\left(10^{-7} \mathrm{M}\right)$ without FBS. Culture with insulin caused a significant increase in PI3K mRNA expression in the wild-type cells cultured for 24 and 48 h (Fig. 2B). This increase was not seen in the transfectants. Insr mRNA expression was not significantly changed in the wild-type cells or transfectants cultured in the presence of insulin $\left(10^{-7} \mathrm{M}\right)$ (Fig. 2A). In addition, culture with insulin $\left(10^{-7} \mathrm{M}\right)$ failed to have a significant effect on GLUT 2 and G3PDH mRNA expression in the wild-type cells and transfectants (Fig. 3). The effect of increasing concentrations of insulin on the expression of Insr, PI3K, GLUT 2, or G3PDH mRNAs in H4-II-E cells cultured for $48 \mathrm{~h}$ was examined (Fig. 4). The expression of PI3K mRNA in the wild-type cells was significantly increased with $10^{-8}$ or $10^{-9} \mathrm{M}$ of insulin (Fig. 4B). This 
A. Insr
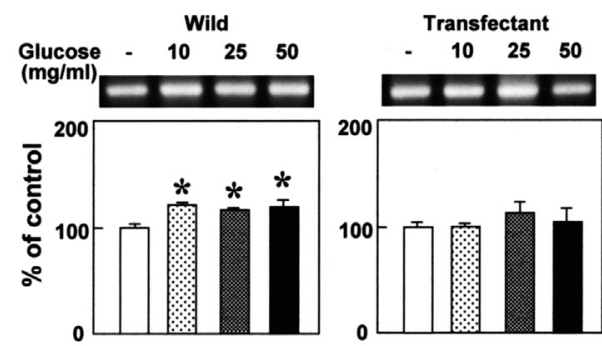

C. GLUT 2

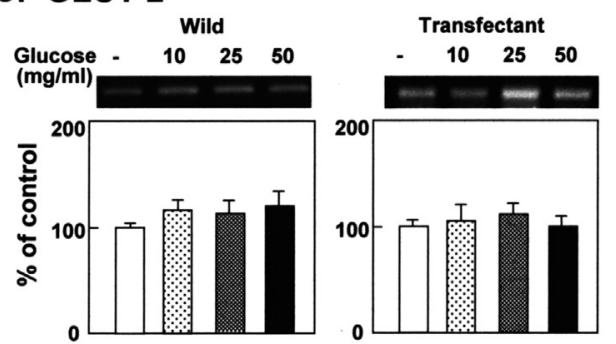

B. PI3K

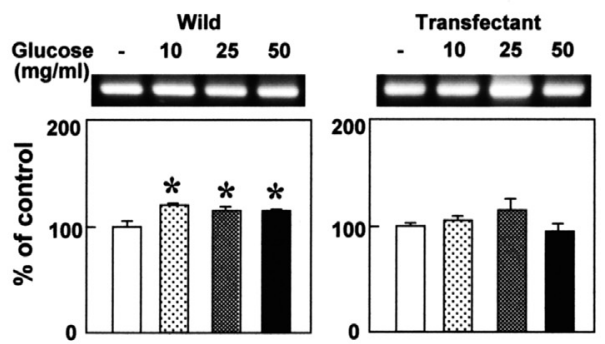

D. G3PDH

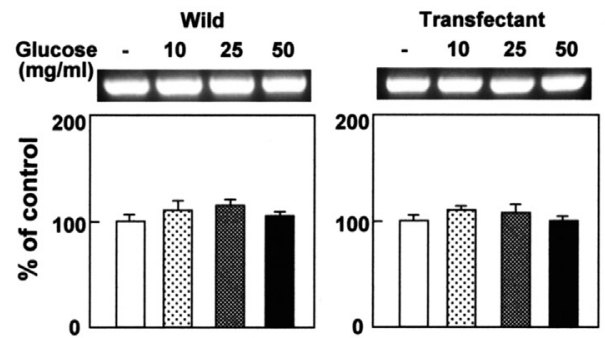

Figure 5. Effect of glucose on insulin receptor (Insr) (A) phosphatidylinositol 3-kinase (PI3K) (B), glucose transporter 2 (GLUT 2) (C), or G3PDH (D) mRNA expression in the cloned rat hepatoma H4-II-E cells (wild-type; W) or regucalcin/pCXN2-transfected cells (T). Cells were cultured for $72 \mathrm{~h}$ in a medium containing FBS (10\%) to obtain subconfluent monolayers. After medium change, cells with subconfluency were cultured for $24 \mathrm{~h}$ in medium with or without supplementation of glucose $(10,25$, and $50 \mathrm{mg} / \mathrm{ml}$ of medium). The figure shows one of four experiments with separate samples. The densitometric data for mRNA levels were indicated as $\%$ of the control (none) of wild-type cells (mean \pm SEM of four experiments). ${ }^{*}<<0.01$, compared with the control (none) value.

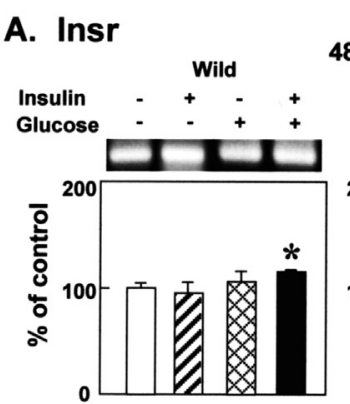

$48 \mathrm{~h}$

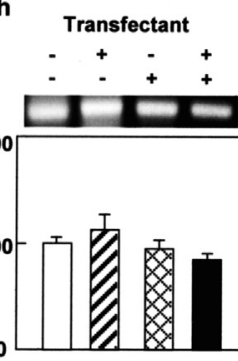

\section{GLUT 2}

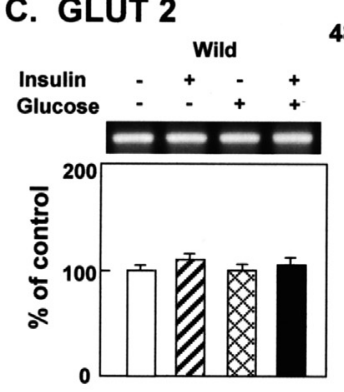

\section{B. PI3K}

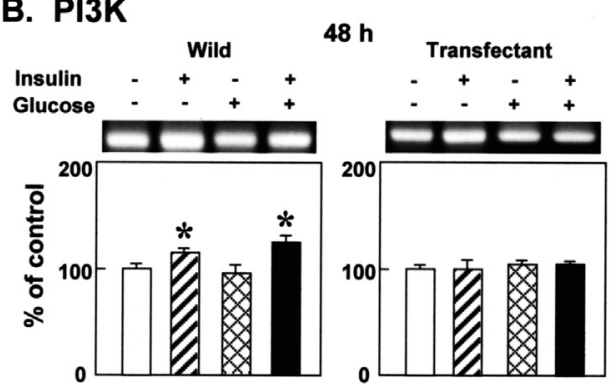

\section{G3PDH}

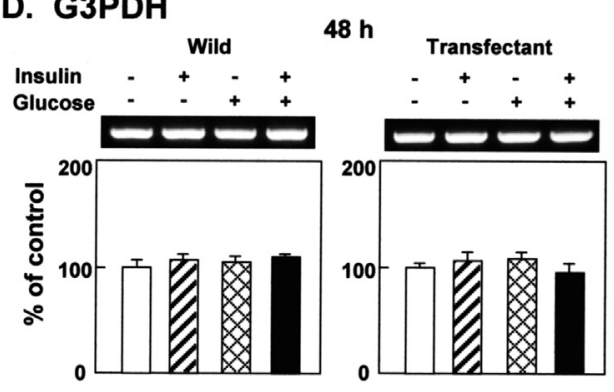

Figure 6. Effect of glucose on insulin receptor (Insr) (A) phosphatidylinositol 3-kinase (PI3K) (B), glucose transporter 2 (GLUT 2) (C), or G3PDH (D) mRNA expression in the cloned rat hepatoma H4-II-E cells (wild-type; W) or regucalcin/pCXN2-transfected cells (T). Cells with subconfluency were cultured $24 \mathrm{~h}$ in medium containing either vehicle or insulin $\left(10^{-7} \mathrm{M}\right)$ with or without supplementation of glucose $(50 \mathrm{mg} / \mathrm{ml}$ of medium). The figure shows one of four experiments with separate samples. The densitometric data for mRNA levels were indicated as $\%$ of the control (none) of wild-type cells (mean \pm SEM of four experiments). ${ }^{*} \mathrm{p}<0.01$ compared with the control (none) value.

increase was not seen in the transfectants. The expression of Insr, GLUT 2, and G3PDH mRNAs in the wild-type cells or transfectants was not significantly changed in the presence of insulin $\left(10^{-9}-10^{-7} \mathrm{M}\right)$.

Effect of glucose supplementation on gene expression of insulin signaling-related proteins in H4-II-E cells over- expressing regucalcin. The wild-type cells and transfectants with subconfluency were cultured for $48 \mathrm{~h}$ in a medium containing either vehicle or glucose $(10,25$, or $50 \mathrm{mg} / \mathrm{ml}$ of medium) without FBS. Supplementation of glucose $(10,25$, or $50 \mathrm{mg} / \mathrm{ml}$ ) caused a significant increase in Insr and PI3K mRNA levels in the H4-II-E wild-type cells (Fig. 5A and B). These increases were not observed in the transfectants. The 

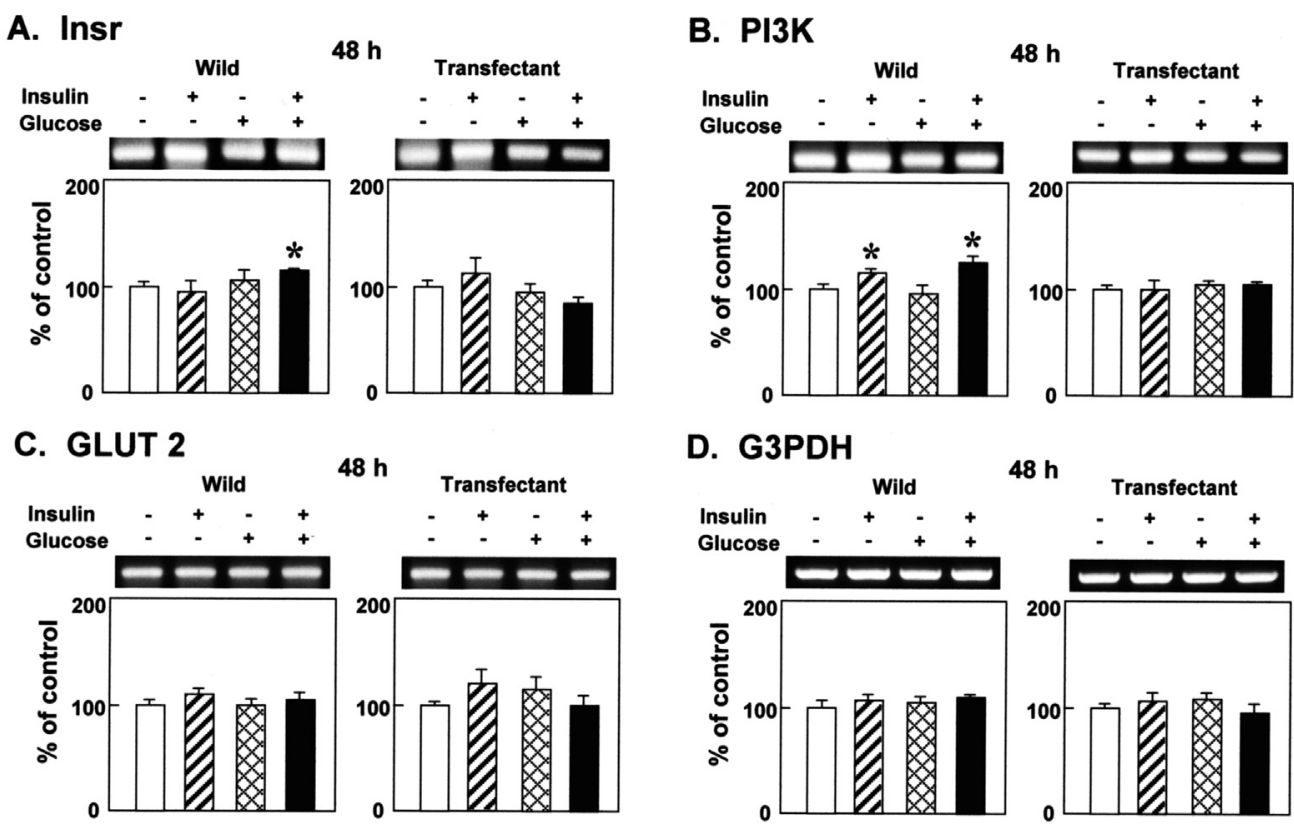

Figure 7. Effect of insulin on insulin receptor (Insr) (A) phosphatidylinositol 3-kinase (PI3K) (B), glucose transporter 2 (GLUT 2) (C), or G3PDH (D) mRNA expression in the cloned rat hepatoma H4-II-E cells (wild-type; W) or regucalcin/pCXN2-transfected cells (T). Cells with subconfluency were cultured $48 \mathrm{~h}$ in a medium containing either vehicle or insulin $\left(10^{-7} \mathrm{M}\right)$ with or without supplementation of glucose $(50 \mathrm{mg} / \mathrm{ml}$ of medium). The figure shows one of four experiments with separate samples. The densitometric data for mRNA levels were indicated as \% of the control (none) of wild-type cells (mean \pm SEM of four experiments). ${ }^{\mathrm{p}}<0.01$ compared with the control (none) value.

A. Insr

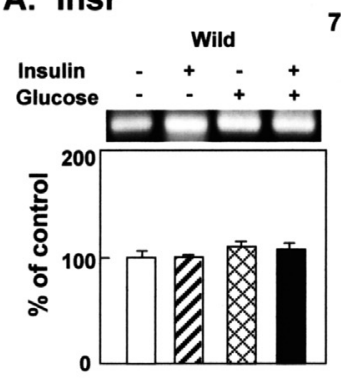

$72 \mathrm{~h}$

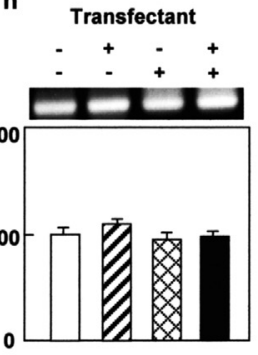

\section{GLUT 2}

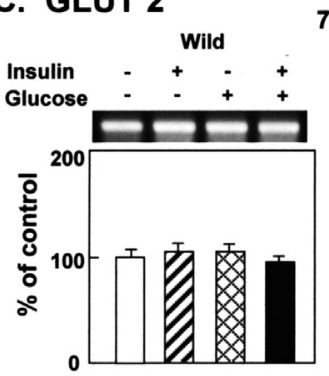

$72 \mathrm{~h}$
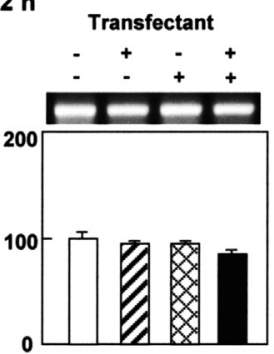

B. PI3K

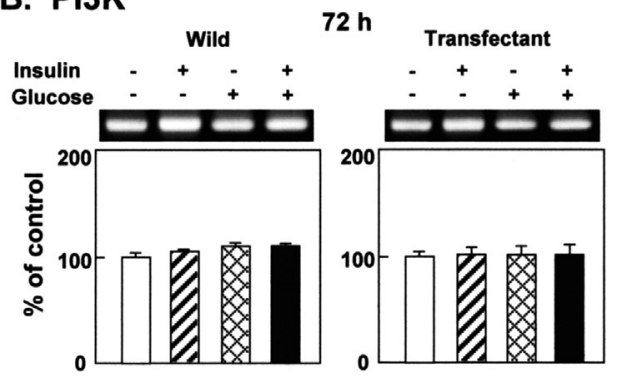

D. G3PDH

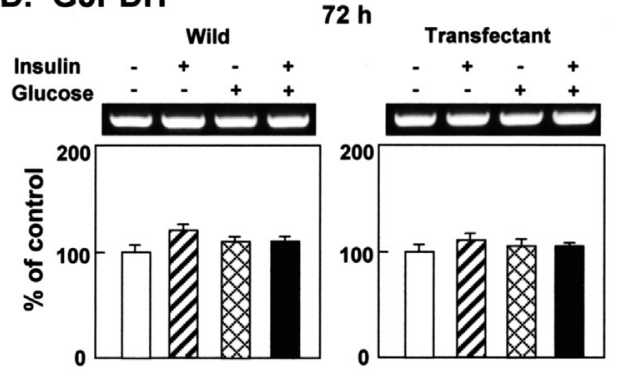

Figure 8. Effect of insulin on insulin receptor (Insr) (A) phosphatidylinositol 3-kinase (PI3K) (B), glucose transporter 2 (GLUT 2) (C), or G3PDH (D) mRNA expression in the cloned rat hepatoma H4-II-E cells (wild-type; W) or regucalcin/pCXN2-transfected cells (T). Cells with subconfluency were cultured $72 \mathrm{~h}$ in a medium containing either vehicle or insulin $\left(10^{-7} \mathrm{M}\right)$ with or without supplementation of glucose $(50 \mathrm{mg} / \mathrm{ml}$ of medium). The figure shows one of four experiments with separate samples. The densitometric data for mRNA levels were indicated as \% of the control (none) of wild-type cells (mean \pm SEM of four experiments). Data were not significant.

expression of GLUT 2 and G3PDH mRNAs was not significantly changed in the wild-type cells or transfectants (Fig. 5C and D).

Effects of insulin and glucose on gene expression of insulin signaling-related proteins in H4-II-E cells overexpressing regucalcin. The effects of the combination of insulin and glucose supplementation on gene expression in the H4-II-E wild-type cells and transfectants were examined. Cells with subconfluency were cultured for 24,48 , or $72 \mathrm{~h}$ in a medium containing either vehicle, insulin $\left(10^{-7} \mathrm{M}\right)$, glucose $(50 \mathrm{mg} / \mathrm{ml}$ of medium), or insulin $\left(10^{-7} \mathrm{M}\right)$ plus glucose $(50 \mathrm{mg} / \mathrm{ml})$. Culture with insulin or glucose for $24 \mathrm{~h}$ caused a significant increase in Insr and PI3K mRNA expression in the wild-type 
cells (Fig. 6A and B). However, the presence of insulin and glucose failed to have a more potent effect on the expression levels of these genes in the wild-type cells. Culture with insulin and glucose for $48 \mathrm{~h}$ caused a significant increase in Insr RNA levels in the wild-type cells, although the gene expression was not significantly changed in the presence of insulin or glucose alone (Fig. 7A). PI3K mRNA levels were significantly increased in the wild-type cells cultured for $48 \mathrm{~h}$ in the presence of insulin alone or insulin plus glucose (Fig. 7B). These increases were not observed in the transfectants (Fig. 7A and B). Culture with insulin, glucose, or insulin plus glucose for $72 \mathrm{~h}$ had no significant effect on the expression of Insr, PI3K, GLUT 2, and G3PDH mRNAs in the wild-type cells or the transfectants (Fig. 8). The cell response to insulin on glucose supplementation appeared to be weakened in the cloned rat hepatoma H4-II-E cells cultured for $72 \mathrm{~h}$. The expression of GLUT 2 and G3PDH mRNA levels was not significantly changed in the wild-type cells or transfectants cultured for 24,48 , or $72 \mathrm{~h}$ in the presence of insulin, glucose, or insulin plus glucose (Figs. 6-8).

\section{Discussion}

Hyperlipidemia is induced in regucalcin transgenic rats with increasing age (23). Overexpression of regucalcin has been shown to enhance glucose utilization and lipid production in cloned rat hepatoma H4-II-E cells, and to induce insulin resistance in the cells (24). Previous studies have shown that insulin resistance may be modeled in H4-II-E liver cells in tissue culture with the use of the cytokine tumor necrosis factor- $\alpha(\mathrm{TNF}-\alpha)$ and insulin (30). From the proteome of H4II-E cells exposed to insulin and TNF- $\alpha$, it has been proposed that regucalcin has a role associated with proteins which are involved in insulin resistance (31). This was confirmed by our previous observations that overexpression of regucalcin plays a role in inducing insulin resistance in H4-II-E cells (24).

The present study was undertaken to determine whether overexpression of regucalcin has an inhibitory effect on gene expression of insulin signaling-related proteins in the cloned rat hepatoma H4-II-E cells in vitro. We determined the expression of Insr, PI3K, and GLUT 2 mRNAs in the cloned rat hepatoma H4-II-E cells overexpressing regucalcin using RT-PCR analysis. Overexpression of regucalcin was found to enhance GLUT 2 mRNA in H4-II-E cells, although it failed to have a significant effect on Insr, PI3K, or G3PDH mRNA expression in the cells cultured in the absence of insulin. The expression of GLUT 2 mRNA in transfectants may be partly involved in the enhancement of glucose utilization in the H4II-E cells overexpressing regucalcin (24).

Overexpression of regucalcin was found to have a suppressive effect on the expression of Insr or PI3K mRNAs enhanced after culture with insulin, glucose supplementation, or insulin plus glucose addition. These results suggest that overexpression of regucalcin suppresses gene expression of insulin signaling-related proteins. This suggests that overexpression of regucalcin induces insulin resistance in the cloned rat hepatoma H4-II-E cells in vitro. Meanwhile, the mRNA expression of acetyl-CoA carboxylase, HMG-CoA reductase, glucokinase, and pyruvate kinase, which are related to glucose and lipid metabolism in liver cells, in the cloned rat hepatoma H4-II-E cells was not significantly changed after culture with or without glucose supplementation in the presence of insulin (24). The suppressive effect of regucalcin on Insr and PI3K mRNA expression may be important in inducing insulin resistance in the cloned rat hepatoma H4-II-E cells overexpressing regucalcin.

Regucalcin transgenic rats have been shown to induce a remarkable increase in lipid components in serum (23). The mechanism is unknown, however. A decrease in lipid component and glycogen in the liver tissues has been found in regucalcin transgenic rats in vivo (32). Overexpression of regucalcin has been shown to enhance glucose utilization and lipid production in the cloned rat hepatoma H4-II-E cell model in vitro, and to regulate the effect of insulin in the cells (24). In addition, overexpression of regucalcin was found to have a suppressive effect on gene expression of Insr and PI3K mRNAs which are related to insulin signaling in liver cells. It has been speculated that the regulatory effect of regucalcin in liver tissues, which is related to insulin signaling, is partly involved in hyperlipidemia induced in regucalcin transgenic rats.

In conclusion, it has been demonstrated that overexpression of regucalcin has a suppressive effect on insulin receptor (Insr) and PI3K mRNA expression which are involved in insulin signaling in the cloned rat hepatoma H4-II-E cells.

\section{References}

1. Yamaguchi M and Yamamoto T: Purification of calcium binding substance from soluble fraction of normal rat liver. Chem Pharm Bull 26: 1915-1918, 1978.

2. Yamaguchi M: Physicochemical properties of calcium-binding protein isolated from rat liver cytosol: $\mathrm{Ca}^{2+}$-induced conformation changes. Chem Pharm Bull 36: 286-290, 1988.

3. Yamaguchi $\mathrm{M}$ : A novel $\mathrm{Ca}^{2+}$-binding protein regucalcin and calcium inhibition. Regulatory role in liver cell function. In: Kohama K (ed). Calcium Inhibition. Japan Sci Soc Press, Tokyo; CRC Press, Boca Raton, pp19-41, 1992.

4. Shimokawa $\mathrm{N}$ and Yamaguchi $\mathrm{M}$ : Molecular cloning and sequencing of the cDNA coding for calcium-binding protein regucalcin from rat liver. FEBS Lett 327: 251-255, 1993.

5. Misawa $\mathrm{H}$ and Yamaguchi $\mathrm{M}$ : The gene of $\mathrm{Ca}^{2+}$-binding protein regucalcin is highly conserved in vertebrate species. Int $\mathrm{J}$ Mol Med 6: 191-196, 2000.

6. Shimokawa N, Matsuda Y and Yamaguchi M: Genomic cloning and chromosomal assignment of rat regucalcin gene. Mol Cell Biochem 151: 157-163, 1995.

7. Thiselton DL, McDowall J, Brandau O, Ramser J, d'Esposite F, Bhattacharga SS, Ross MT, Haradeastle AJ and Meindl A: An integrated, functionally annotated gene map of the DXS80269ELK1 interval of human Xp 11.3-Xp 11.23. Potential hotspot for neurogenetic disorders. Genomics 79: 560-572, 2002.

8. Murata $\mathrm{T}$ and Yamaguchi M: Promoter characterization of the rat gene for $\mathrm{Ca}^{2+}$-binding protein regucalcin. Transcription regulation by signaling factor. J Biol Chem 274: 1277-1285, 1999.

9. Misawa $\mathrm{H}$ and Yamaguchi $\mathrm{M}$ : Molecular cloning and sequencing of the cDNA coding for a novel regucalcin gene promoter region-related protein in rat, mouse and human liver. Int J Mol Med 8: 513-520, 2001.

10. Misawa $H$ and Yamaguchi $M$ : Identification of transcription factor in the promoter region of rat regucalcin gene: Binding of nuclear factor I-AI to TTGGC motif. J Cell Biochem 84: 795-802, 2002.

11. Sawada N and Yamaguchi M: Overexpression of RGPR-p117 enhances regucalcin gene promoter activity in cloned normal rat kidney proximal tubular epithelial cells: Involvement of TTGGC motif. J Cell Biochem 99: 589-597, 2006. 
12. Yamaguchi M: Role of regucalcin in calcium signaling. Life Sci 66: 1769-1780, 2000.

13. Yamaguchi M: The role of regucalcin in nuclear regulation of regenerating liver. Biochem Biophys Res Commun 276: 1-6, 2000.

14. Yamaguchi M: Role of regucalcin in maintaining cell homeostasis and function (Review). Int J Mol Med 15: 371-389, 2005.

15. Yamaguchi $\mathrm{M}$ and Tai $\mathrm{H}$ : Calcium-binding protein regucalcin increases calcium-independent proteolytic activity in rat liver cytosol. Mol Cell Biochem 112: 89-95, 1992.

16. Fukaya $Y$ and Yamaguchi M: Regucalcin increases superoxide dismutase activity in rat liver cytosol. Biol Pharm Bull 27: 1444-1446, 2004.

17. Nakagawa T, Sawada N and Yamaguchi M: Overexpression of regucalcin suppresses cell proliferation of cloned normal rat kidney proximal tubular epithelial NRK52E cells. Int J Mol Med 16: 637-643, 2005.

18. Yamaguchi $\mathrm{M}$ and Daimon $\mathrm{Y}$ : Overexpression of regucalcin suppresses cell proliferation in cloned rat hepatoma H4-II-E cells: Involvement of intracellular signaling factors and cell cycle-related genes. J Cell Biochem 95: 1169-1177, 2005.

19. Izumi T and Yamaguchi M: Overexpression of regucalcin suppresses cell death in cloned rat hepatoma-II-E cells induced by tumor necrosis factor- $\alpha$ or thapsigargin. J Cell Biochem 92: 296-306, 2004.

20. Nakagawa T and Yamaguchi M: Overexpression of regucalcin suppresses apoptotic cell death in cloned normal rat kidney proximal tubular epithelial NRK52E cells. Change in apoptosisrelated gene expression. J Cell Biochem 96: 1274-1285, 2005.

21. Yamaguchi M, Morooka Y, Misawa H, Tsurusaki Y and Nakajima R: Role of endogenous regucalcin in transgenic rats: Suppression of kidney cortex cytosolic protein phosphatase activity and enhancement of heart muscle microsomal $\mathrm{Ca}^{2+}$ ATPase activity. J Cell Biochem 86: 520-529, 2002.

22. Yamaguchi M, Misawa H, Uchiyama S, Morooka Y and Tsurusaki Y: Role of endogenous regucalcin in bone metabolism: Bone loss is induced in regucalcin transgenic rats. Int J Mol Med 10: 377-383, 2002.
23. Yamaguchi M, Igarashi A, Uchiyama $\mathrm{S}$ and Sawada $\mathrm{N}$ Hyperlipidemia is induced in regucalcin transgenic rats with increasing age. Int J Mol Med 14: 647-651, 2004.

24. Nakashima C and Yamaguchi M: Overexpression of regucalcin enhances glucose utilization and lipid production in cloned rat hepatoma H4-II-E cells: Involvement of insulin resistance. J Cell Biochem 99: 1582-1592, 2006.

25. Misawa H, Inagaki $H$ and Yamaguchi M: Suppression of cell proliferation and deoxyribonucleic acid synthesis in cloned rat hepatoma H4-II-E cells overexpressing regucalcin. J Cell Biochem 84: 139-143, 2002.

26. Chomczyshi P and Sacchi N: Single-step method of RNA isolation by acid guanidium thiocyanate-phenol-chloroform extraction. Anal Biochem 162: 156-159, 1987.

27. Szpirer C, Szpirer J, Vanvooren P, Riviere M, Maget B, Svoboda M, Shiozawa M, Simon JS, Jacob HJ and Koike G: Localization of the rat genes encoding glucagons, glucagon receptor, and insulin receptor, candidates for diabetes mellitus susceptibility loci: Mamm Genome 8: 586-588, 1997.

28. Inukai K, Anai M, Breda EV, Hosaka T, Katagiri H, Funaki M, Fukushima Y, Ogihara T, Yazaki Y, Kikuchi M, Oka Y and Asano T: A novel 55-kDa regulatory subunit for phosphatidylinositol 3-kinase structurally similar to p55PIK is generated by alternative splicing of the p85 $\alpha$ gene. J Biol Chem 271: 5317-5320, 1996

29. Thorens B, Sarkar HK, Kaback HR, and Lodish HF: Cloning and functional expression in bacteria of a novel glucose transporter present in liver, intestine, kidney, and beta-pancreatic islet cells. Cell 55: 281-290, 1988 .

30. Soloman SS, Mishra SK, Palazzolo MR, Postlethwaite AE and Seyer JM: Identification of specific sites in the TNF- $\alpha$ molecule promoting insulin resistance in H4-II-E cells. J Lab Clin Med 130: 139-146, 1997

31. Solomon SS, Buss N, Shull J, Monnier S, Majumdar G, W J and Gerling IC: Proteome of H4-II-E (liver) cells exposed to insulin and tumor neocrosis factor- $\alpha$ : Analysis of proteins involved in insulin resistance. J Lab Clin Med 145: 275-283, 2005.

32. Yamaguchi M and Nakagawa T: Change in lipid components in the adipose and liver tissues of regucalcin transgenic rats with increasing age: suppression of leptin and adiponectin gene expression. Int J Mol Med 20: 323-328, 2007. 